Archived version from NCDOCKS Institutional Repository - http://libres.uncg.edu/ir/asu/

Bergman, J. Z., Westerman, J. W., Bergman, S. M., \& Daly, J. P. (2013). Narcissism, materialism, and environmental ethics in business students. Journal of Management Education. Published by Sage (ISSN: 1552-6658). Advance online publication. doi:10.1177/1052562913488108. The version of record is available from: www.sagepub.com

\title{
Narcissism, Materialism, and Environmental Ethics in Business Students
}

Jacqueline Z. Bergman, James W. Westerman, Shawn M. Bergman, Jennifer Westerman, and Joseph P. Daly

\begin{abstract}
We investigate the relationships between narcissism, materialism, and environmental ethics in undergraduate business students. Data were collected from business students $(n=405)$ at an Association to Advance Collegiate Schools of Business-accredited business school at a comprehensive state university. Results indicate that narcissism has an indirect effect on business students' environmental ethics. Narcissism was significantly related to materialism, and materialism was significantly related to lower levels of environmental ethics. Considering increasing levels of narcissism among business students, we discuss the potential for future research and potential intervention strategies.
\end{abstract}


A review of research on business ethics found that over a recent 10-year period, the most prominent ethics theme was environmentalism, comprising $30 \%$ of all ethics articles in one leading management journal (Robertson, 2008). This focus is not surprising, as there exists a global scientific consensus that climate change will result in unprecedented alterations to the way humans live on earth (Intergovernmental Panel on Climate Change, 2007), and industry accounts for $37 \%$ of global carbon dioxide emissions (Intergovernmental Panel on Climate Change, 2007). As noted by Speth (2009), at the current rates of worldwide industry growth, we are facing the potential of "an enormous increase in environmental deterioration, just when we need to move strongly in the opposite direction" (p. 6). The evidence continues to mount in support of Hawken's (1993) dire warning that "every living system on Earth is in decline" (p. xii).

The larger issue here for business educators may be the necessity to ask the fundamental question: "What is business education for?" If it is not to educate students to address the environmental crises, then we may not be educating our students for the critical challenges they will face in their lifetimes.

To create an enduring society, we will need a system of commerce and production where each and every act is inherently sustainable and restorative. Business will need to integrate economic, biologic, and human systems to create a sustainable method of commerce . . . Just as every act in an industrial society leads to environmental degradation, regardless of intention, we must design a system where the opposite is true. (Hawken, 1993, p. xiv)

Haigh and Griffiths (2009) apply this logic and argue that climate change, with its effects on business infrastructure, resources, products, and markets, provides sufficient rationale (notwithstanding the moral and ethical considerations) to consider the natural environment as a primary stakeholder in strategic management decision making. Higher education may need to play a more central role in the adaptation toward sustainable business practices: "Our duty towards [the] education of future professionals is to make it possible for them to participate in the necessary transformation" (Svanstrom, Lozano-Garcia, \& Rowe, 2008, p. 340).

This research examines the relationship between student narcissism, materialism, and a potential social cost of enhanced levels of narcissism and materialism-environmental ethics. As society recognizes the impact of economic activities on nature, and consumers increase their demands for businesses to adopt environmentally responsible behavior, 
management educators must ensure that our future business leaders are capable and caring businesspersons who represent positive role models.

However, recent research suggests worrying phenomena: Business students may lack empathy, possess enhanced levels of self-interest, and may exploit common resources (Campbell, Bush, Brunell, \& Shelton, 2005). A study by Westerman, Bergman, Bergman, and Daly (2012) indicates that the personality characteristic of narcissism is higher among business students than among students of other disciplines. Narcissism has also been linked to a wide range of undesirable outcomes in the workplace, including white- collar crime (Blickle, Schlegel, Fassbender, \& Klein, 2006), risky decision making (Campbell, Goodie, \& Foster, 2004), and blaming others for personal failure (Kernis \& Sun, 1994).

If our future business leaders carry their higher levels of narcissistic behavior into the workplace, it raises important issues regarding the social costs of narcissism. The possible role that personality may play in environmental ethics has been relatively unexamined in the research literature, and we believe stable personality traits, especially narcissism, may help explain why business students differ in their environmentally ethical behavior. Thus, this research seeks to examine the relationships among narcissism, material- ism, and environmental ethics in undergraduate business students and to determine the extent to which management educators may need to refocus their efforts toward attitudinal learning with respect to materialism and environmental issues. ${ }^{1}$

\section{Business Students and Materialism}

Materialism is defined as a chronic focus on lower order needs, such as phys- ical comfort and safety, over higher order needs, such as selfexpression, belonging, and quality of life (Inglehart, 1990), or alternatively as a value that represents a "mind-set or constellation of attitudes regarding the relative importance of acquisition and possession of objects in one's life" (Richins \& Dawson, 1992, p. 307). Defining materialism as a value (as opposed to a personality trait; e.g., Belk, 1985) is congruent with the idea that materialism involves the extent to which one places importance on possessions and their acquisition as a necessary means to achieve desirable end states. Thus, the acquisition of possessions is not the ultimate goal; such acquisition is a way to achieve other ends, such as happiness or admiration. Ironically, however, such materialistic values are consistently found to have a negative effect on happiness and well-being (Kasser \& Kanner, 2004). 
Many believe that enhanced levels of materialism may be disproportionately present in university business students, and some have gone so far as to argue that this is, at least partly, the result of business schools advocating materialistic greed, profit, and the acquisition of wealth over all other goals (Giacalone \& Wargo, 2009). There is evidence to suggest that business school education and its environment may have harmful effects on the values and behavior of our students (see Pfeffer, 2005). For example, a study conducted by the Aspen Institute (2001) found that the values of MBA students changed during their 2 years in graduate school; maximizing shareholder value became more important whereas customers and employees became less important. Another study found that the relationship between firm size and corporate illegal activity becomes stronger as the percentage of top management team members with an MBA degree increases (Williams, Barrett, \& Brabston, 2000).

Although it remains unclear whether findings such as these are due to selfselection into business schools or are the result of the educational process itself, there is direct evidence that business school students possess more materialistic values than students in other subjects. In a comparison of business and education students, business majors more strongly endorsed extrinsic values (with a particular emphasis on personal financial success), showed more signs of internal distress, displayed lower levels of wellbeing, and had more substance abuse problems (Vansteenkiste, Duriez, Simons, \& Soenens, 2006). Furthermore, the differences in self-reported well-being and substance use between business and education students was fully explained by the type of values with which each group was primarily concerned (business students cited wealth accumulation and education students cited helping people in need; Vansteenkiste et al., 2006). Similarly, Robak, Chiffriller, and Zappone (2007) found that business students were more motivated to make money than students with a psychology major and were subject to more negative mood states like anger and depression.

\section{The Relationship Between Narcissism and Materialism}

As with materialism, there is evidence suggesting that business students possess higher levels of narcissism than students in other disciplines (Westerman et al., 2012), and we would expect to see a relationship between narcissism and materialism. Theoretically, this link is supported by the concept of terminal materialism, which refers to individuals using possessions to create envy and obtain the admiration of others or to 
achieve status (Rochberg-Halton, 1986). Thus, being envied and having status are the ultimate goals, as opposed to acquiring possessions, as possessions are simply a means to an end. The possession and flaunting of expensive, high-prestige items are one obvious way to ensure attention, obtain higher status, and receive recognition from peers, particularly in a relatively materialistic society such as in the United States (Belk, 1985; Richins \& Dawson, 1992). Individuals high in narcissism display an excessive reliance on, and place great importance on, status and recognition (American Psychological Association, 2000). Narcissists' strong desire to achieve and display status likely leads to higher levels of materialism. Furthermore, those high in narcissism possess an inflated, yet fragile, sense of self-esteem and become dependent on social sources for affirmation (Morf \& Rhodewalt, 2001). Self-doubt and feelings of inadequacy appear to be linked to an individual's disproportionate focus on materialistic values (Chang \& Arkin, 2002; Richins \& Dawson, 1992). Thus, accumulating material goods and receiving the accompanying admiration from others is one way that narcissists may build their sense of self-worth (Cisek, Hart, \& Sedikides, 2008).

Narcissists tend to be hypervigilant for ego threats, and when such threats occur, they initially activate worthlessness and then rapidly and automatically inhibit it in order to protect their sense of grandiosity, which further supports the relationship between narcissism and materialism. These findings highlight the important role that worthlessness plays in the selfregulation of narcissists (Horvath \& Morf, 2009). In essence, materialism may operate as a protection mechanism against implicit feelings of worthlessness. The acquisition of possessions may work to counteract potential feelings of worthless- ness; one cannot be considered worthless if one owns possessions of "worth."

Research tends to support the proposition that narcissism is associated with stronger materialistic values. For example, Rose (2007) found positive relationships between narcissism and both materialism and compulsive buying. Furthermore, Kasser and Ryan (1996) found a link between narcissism and aspirations of wealth and fame. Cisek et al. (2008) found that narcissists are significantly more likely to buy items that make them feel and look good rather than those that satisfy practical needs. Although there exists a fair amount of evidence suggesting a relationship between various aspects of materialism and enhanced narcissism, to date research has not explicitly examined the relationship between materialism (in all of its dimensions) and narcissism among business students. 
Hypothesis 1a: Business student narcissism will be positively related to materialism.

\section{The Relationship Between Narcissism and Environmental Ethics}

The United Nations (2004) defines environmental ethics as follows: "Environmental ethics . . . is the study of normative issues and principles relating to human interactions with the natural environment, and to their con- text and consequences" (p. 6). Environmental ethics is considered applied ethics and should be used to "guide individuals, corporations and governments in determining the principles affecting their policies, their lifestyles, and their actions across the entire range of environmental and ecological problems, and for the appraisal of such actions, lifestyles, and policies" (p. 6). At the level of the individual, empathy and altruism are often considered central to environmental concern. The capacity to feel an emotional response based on the perceived welfare of another, and the desire to help others and act in the interest of others, should be directly related to the concern one has for the natural environment. For example, research findings have shown that taking the perspective of animals being harmed leads to significantly higher levels of environmental concern (Schultz, 2000). One of the defining characteristics of narcissists is that they lack empathy (American Psychological Association, 2000). Narcissists tend to disregard others' rights and feelings and are unable to take the perspective of others. They are overly focused on themselves and their own needs and interests. Such egoistic concerns make it unlikely that those high in narcissism will worry much about the consequences of their behavior on the environment.

A significant amount of research has linked the existence of environmental problems to human tendencies to act in our own interest (e.g., Diekmann \& Preisendorfer, 1998; Hardin, 1968; Kaiser, Ranney, Hartig, \& Bowler, 1999). In fact, engaging in conservation efforts is typically presumed to stem from intrinsic concern about nature and the well-being of the planet (e.g., Bamberg \& Schmidt, 2003; Fransson \& Gärling, 1999; Stern \& Dietz, 1994). Thus, individuals whose values are more egoistic possess a lower intrinsic concern about nature and opt to engage in proenvironment behavior only when the perceived benefits outweigh the perceived costs for them person- ally (De Groot \& Steg, 2008). 
Research findings also suggest that narcissists will place their own interests above others' and are likely to exploit others and common resources to obtain short-term success. Campbell et al. (2005) investigated the impact of narcissism in the classic social dilemma, the tragedy of the commons, where short-term self-interests are pitted against the long-term interests of a group regarding the use of a common resource (in this case, a renewable forest). During the competitive simulation, narcissists desired significantly more profit and experienced greater short-term success. However, narcissists depleted the common resource more rapidly such that the total reward for the group was diminished, suggesting that the social and environmental costs of narcissism may be high. Thus, the present research examines whether narcissism among business students has a direct effect on their environmental ethics.

Hypothesis 1b: Business student narcissism will be negatively related to environmental ethics.

\section{The Relationship Between Materialism and Environmental Ethics}

High levels of consumption are often seen as the primary cause of ecological degradation (Princen, 1997). An emphasis on material possessions is often linked with little or no concern for nature or the environment, as materialism and consumption are in direct contrast to the simplicity that is typically associated with ecological responsibility (Lasch, 1978; Linden, 1979; Richins \& Dawson, 1992). Kilbourne and Pickett (2008) argue that cognitive dissonance plays a key role in the link between materialism and environmental beliefs. Individuals do not wish to see themselves as potentially destroying the environment through their high consumption. Yet the values associated with materialism are quite prevalent in American society. The cognitive dissonance created by these conflicting values is reduced by selectively removing or distorting the information that is inconsistent with one's values. Thus, the individual may reject or deny evidence that human consumption and materialism contribute to environmental decline, in order to maintain his or her primary value of materialism. Research by Kilbourne and Pickett (2008) supports the contention that placing a high value on consumption is negatively related to environmental beliefs and concern. The present study empirically examines the significance of the relationship between materialism and environmental ethics among university business students. 
Hypothesis 2: Business student materialism will be negatively related to their stance on environmental ethics.

\section{Gender Differences in Environmental Ethics}

A considerable volume of research supports the view that gender differences will affect ethical issues in business (Schminke, Ambrose, \& Miles, 2003). Women are perceived to be more sympathetic and more intuitive than men (Heilman, Block, Martell, \& Simon, 1989), and Schein (1973) notes that women are perceived as more helpful and aware of others' feelings. Gilligan $(1977,1982)$ argues that women and men possess fundamentally different moral orientations and that men utilize justice as a criterion shaping their ethical orientation, whereas women operate from a framework of caring as a primary moral orientation. Other work empirically supports this position (e.g., Beekun, Stedham, Westerman, \& Yamamura, 2010; White, 1992, 1994). Furthermore, Arlow's (1991) research indicates that women place less emphasis on expediency and selfish interests when evaluating ethical issues. Khazanchi (1995) found that women are better at recognizing unethical actions in scenarios. Ameen, Guffey, and McMillan (1996) found that female students were better able to identify ethically questionable student activities as more unethical than were male students. Ruegger and King (1992) also reported that women identified several areas of ethical concern as more unacceptable than did men, including performing work that may be harmful or unethical and a firm's duty not to exploit stakeholders. Wehrmeyer and McNeil (2000) found that women in organizations in the United Kingdom were more likely to be actively involved in environmental behavior (conscientious activism) than were their male counterparts. Similarly, women demonstrate stronger feelings regarding ethical issues (Whipple \& Swords, 1992). Kohlberg's $(1981,1984)$ stage approach to moral development has also been shown to have robust gender differences (Boldizar, Wilson, \& Deemer, 1989; Lifton, 1985; Rest, 1986; Thoma, 1986). Finally, as indicated by Hofstede (1998), gender studies seem to indicate that "men tend to stress ego goals more whereas women tend to stress social goals" (p. 11). As a result of this prior research and theory, this study explores whether female business students in the United States have higher levels of environmental ethics than male business students.

Hypothesis 3: Female business students will be higher on environmental ethics than male business students. 


\section{METHOD}

Participants were 405 undergraduate business students at an Association to Advance Collegiate Schools of Business-accredited business school in the southeastern United States. Participation in the study was voluntary, and subjects were recruited from the following business courses: organizational behavior, strategic management, human resource management, entrepreneur- ship, principles of marketing, contemporary issues in management and leadership, and principles of economic theory. Subjects were informed that the study was designed to investigate generational differences among university students and that participation would take approximately 20 minutes. Subjects were apprised that responses would be completely confidential, no compensation would be provided for participating, and there was no penalty for choosing not to participate. Participants were provided sufficient class time to complete a survey, which consisted of demographic information including age and gender, and several inventories representing the independent and dependent variables. The mean age of the final sample was 21.7 years, with a range of 17 to 30 years. The sample was $65 \%$ male $\left(n_{\text {male }}=261\right)$ and $35 \%$ female $\left(n_{\text {female }}=140\right)$, and 4 participants did not indicate their gender.

\section{Measures}

Narcissism. To assess their levels of subclinical narcissism, participants completed the Narcissistic Personality Inventory (NPI; Raskin \& Terry, 1988). The NPI contains 40 paired statements that measure authority, exhibitionism, superiority, entitlement, exploitativeness, vanity, and selfsufficiency. Each pair of statements includes a forced choice between a narcissistic response and a nonnarcissistic response. Respondents were asked to select the statement that best matched their own feelings and beliefs. The following items were included: "Modesty doesn't become me" versus "I am essentially a modest person" and "I can usually talk my way out of anything" versus "I try to accept the consequences of my behavior." Narcissistic responses were summed, and higher scores on the NPI indicated a more narcissistic personality. The NPI has been shown to have adequate reliability and validity (Raskin \& Terry, 1988; Rhodewalt \& Morf, 1995). Cronbach's alpha for the present sample was .83.

Materialism. Materialism was measured using the Material Values Scale (Richins \& Dawson, 1992). The scale consists of 18 items assessing three 
facets: success, acquisition centrality, and acquisitions as the pursuit of happiness. The following sample items were included: "The things I own say a lot about how well I'm doing in life;" "Buying things gives me a lot of plea- sure;" and "l'd be happier if I could afford to buy more things." Participants responded to each item based on a 5-point scale from 1 (strongly disagree) to 5 (strongly agree). Item scores were summed within factor to form indices for each of the three factors and were summed overall to form an overall materialism score. Cronbach's alpha for the present sample was .89 .

Environmental Ethics. The New Ecological Paradigm Scale was used to assess environmental ethics. It offers balance and a broad scope in understanding an individual's environmental sensitivity and is widely used to measure environ- mental orientation (Dunlap, Van Liere, Mertig, \& Jones, 2000). A proecological orientation (seeing the world ecologically) is reflected by a high score on the New Ecological Paradigm Scale and represents proenvironmental beliefs and attitudes on a wide range of issues. Participants responded to 15 items based on a 5-point scale from 1 (strongly disagree) to 5 (strongly agree). The scale consists of five facets: reality of limits to growth, antianthropocentrism, fragility of nature's balance, rejection of the idea that humans are exempt from the constraints of nature, and the possibility of an ecological crisis or catastrophe. Sample items include the following: "When humans interfere with nature it often produces disastrous consequences;" "We are approaching the limit of the number of people the earth can support;" and "Humans were meant to rule over the rest of nature" (reverse scored). Item scores were summed both within factor to form indices for the five factors and overall to form an overall environmental ethics score. Cronbach's alpha for the present sample was .83 . 
Table I. Descriptive Statistics and Correlations.

\begin{tabular}{lcccc}
\hline Variable & 1 & 2 & 3 & 4 \\
\hline Gender & - & & & \\
Narcissism & $.13^{*}$ & - & & \\
Materialism & -.01 & $.24^{* * *}$ & - & $-14^{* * *}$ \\
Environmental ethics & $-.15^{* *}$ & -.06 & 2.88 & 3.39 \\
$M$ & 0.65 & 17.67 & 0.65 & 0.58 \\
SD & 0.48 & 6.55 & \\
\hline
\end{tabular}

Note. Gender is coded female $=0$, male $=1$.

$* p<.05$. **p $<.01$. ***kp $<.001$.

\section{RESULTS}

Descriptive statistics and variable intercorrelations are presented in Table 1. Hypothesis 1 predicted that business student narcissism would be positively related to materialism and negatively related to environmental ethics. As shown in Table 1, narcissism had a significant, positive correlation with materialism, the size of which indicated a medium effect size (Cohen, 1988). Narcissism was not related, however, to environmental ethics. Thus, Hypothesis 1a was supported, whereas Hypothesis $1 \mathrm{~b}$ was not.

Hypothesis 2 posited that business student materialism would be negatively related to environmental ethics. As shown in Table 1, materialism had a significant, negative correlation with environmental ethics, the size of which indicated a small effect size. Thus, Hypothesis 2 was supported.

Although finding significant narcissism-materialism and materialismenvironmental ethics correlations suggested that narcissism had an indirect relationship with environmental ethics, it did not formally test the significance of the suggested indirect effect. As such, the indirect relationship was tested using a bootstrap procedure that drew 2,000 bootstrap samples to create an estimate and standard error (Preacher \& Hayes, 2004) of the indirect effect that narcissism had on environmental ethics through materialism (see Figure 1). Results indicated that narcissism did have a significant indirect relationship, estimate $=-0.003$, $S E=0.001, z=-2.22, p=.026$, with environmental ethics through materialism. 


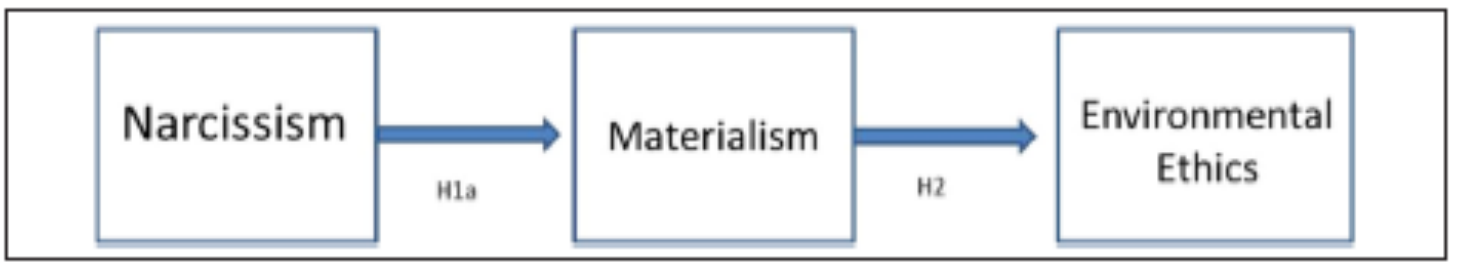

Figure I. Narcissism, materialism, and environmental ethics results.

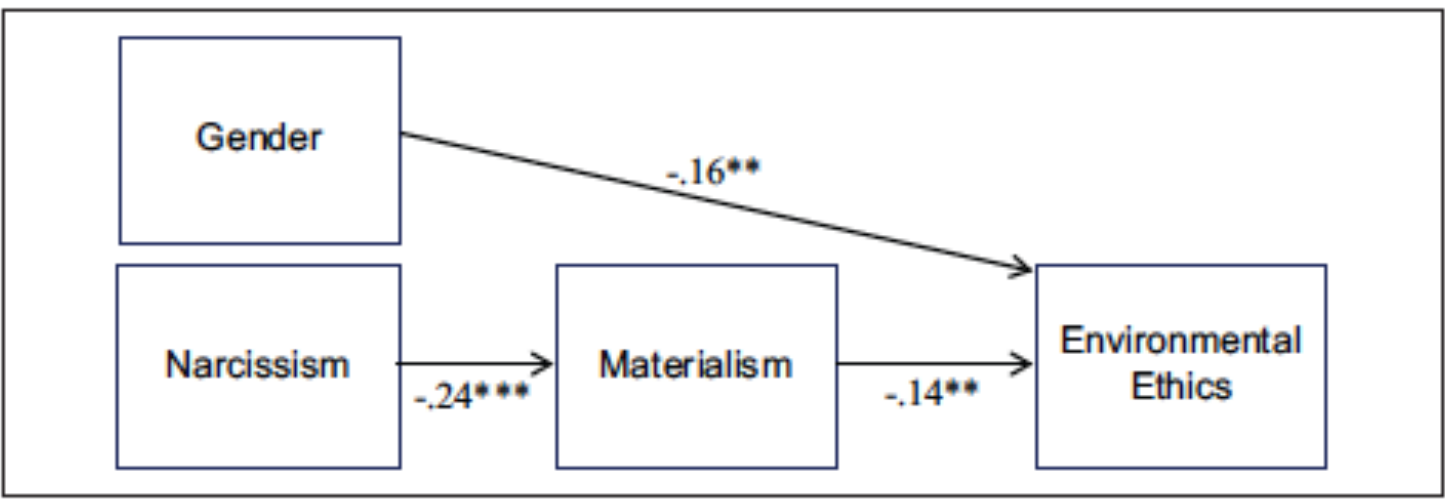

Figure 2. Modified model of narcissism, gender, materialism, and environmental ethics.

Note. Coefficients presented above are completely standardized path weights.

$* p<.05$. * $*$ p $<.01$. *** $<$ <.00I.

In order to test Hypothesis 3, which predicted that female business students would be higher on environmental ethics than male business students, an independent samples $t$ test was conducted. Results indicated that women, $M=3.50, S D=0.50$, had higher average ratings on the environmental ethics scale, $t(339)=3.12, p=.002, d=0.34$, than men, $M$ $=3.32, S D=0.61$. Thus, Hypothesis 3 was supported.

Based on the results of the tests of the study's hypotheses, a model was proposed showing the hypothesized relationships between gender, narcissism, materialism, and environmental ethics (see Figure 2). The model was tested using path analysis in LISREL 8.80 (Jöreskog \& Sörbom, 2006), which allowed for the fit of the overall model to the data to be evaluated, all of the path coefficients in the model to be simultaneously estimated, and the indirect effect of narcissism on environmental ethics to be tested (Preacher \& Hayes, 2008). Results indicated that the proposed model provided excellent fit to the data, $\mathrm{X}^{2}(2)=1.14, p=.564$; normed fit index $=0.98$; standardized root mean square residual $=0.02$; adjusted 
goodness of fit $=0.99$, both gender and materialism were significant predictors of environmental ethics, and narcissism was a significant predictor of materialism. Additionally, results of the indirect test indicated that narcissism had a significant indirect effect, estimate $=-0.003, S E=$ $0.001, z=-2.46, p=.014$, on environmental ethics through materialism.

\section{DISCUSSION}

The results of the current study indicate that narcissism is significantly related to higher levels of materialism in business students. Furthermore, higher materialism is associated with lower environmental ethics. Thus, significantly enhanced levels of narcissism among business students are likely to be problematic for society in that they are associated with both higher levels of materialism and lower environmental ethics. Important in this regard, there is evidence that business schools are disproportionately graduating students with narcissistic tendencies (Westerman et al., 2012). Thus, business education in the United States is facing a challenge of reducing narcissism and materialism and enhancing the environmental ethics of its students.

The lack of a direct relationship in this study between narcissism and environmental ethics was surprising, but this may be due to a variety of factors. First, if an individual high in egoism believes that environmental damage may threaten his or her own well-being, he or she may indeed be concerned about environmental issues (Schultz, 2000). The present study did not examine the extent to which participants believe that environmental damage directly threatens their own well-being. This possible moderator may be worth examining in future research. Second, although many narcissistic behaviors consist of overt displays of grandiosity, in some cases, the narcissist's need for praise and admiration is covert and manifests as apparently self-sacrificing devotion to work or other pursuits (Rodin \& Izenberg, 1996). Although these self-sacrificing behaviors are still attempts to derive admiration and gratification from external sources, these behaviors may appear to be altruistic or prosocial in nature, such as displaying a concern for environmental issues.

Additionally, there is likely to be strong societal pressure to endorse certain values, such as protecting the environment. According to research con- ducted by Generate Insight (Gaudelli, 2009), 69\% of younger generation respondents expressed genuine interest in environmental issues and $76 \%$ emphasized the importance of brands being ecologically conscious. Such endorsement, however, does not necessarily translate 
into actual behavior. Research in social psychology has consistently found that human beings often display an attitude-behavior gap, such that they say one thing and do another (Baron \& Byrne, 1997), and this has been found to hold true for consumers as well (see Carrington, Neville, \& Whitwell, 2010; Hanks, Odom, Roedl, \& Blevis, 2008). Narcissists may feel as much pressure as nonnarcissists to state that they are concerned with the environment; however, their actual behavior may differ quite dramatically, as suggested by their high materialism scores. In a consumer-based society, such as in the United States, where materialism is the norm, societal pressure to shun materialism is likely much less than is pressure to endorse environmentalism. This may allow narcissists to feel free to endorse materialistic values and respond positively to items such as "The things I own say a lot about how well I'm doing in life" or "Buying things gives me a lot of pleasure." As environmental issues have taken on more prominence in the United States, it may be that materialism represents a more culturally appropriate way for business students to mani- fest narcissism.

However, the link between narcissism, materialism, and environmental ethics among business students indicated in this study may also provide an opportunity. Griskevicius, Tybur, and Van den Bergh (2010) examined the idea of "conspicuous conservation." They found that activating status motives led individuals to opt for prosocial "green" products over more luxurious "nongreen" products when shopping in public but not when shopping in private. Furthermore, this tendency occurred especially when such products cost more, not less, than the "nongreen" products. As those high in narcissism are preoccupied with receiving attention and overly concerned with attaining high status in the eyes of others (Millon, 1996), narcissists may be disproportionately influenced by opportunities within our classrooms (and organizations) to demonstrate status in a manner that reflects environmental concern. Furthermore, as mentioned above, Schultz (2000) suggested that if an individual high in egoism believes that environmental damage may threaten his or her own well-being, he or she may become more concerned about environ- mental issues. This may provide an opportunity for educators (and organizations) to adapt to increasing levels of narcissism in a manner that does not come at the expense of environmental ethics and behavior by sensitizing narcissists to the personal risks of environmental degradation in our business ethics courses. 


\section{Implications for Business Education}

The results of the present study suggest that management educators may need to refocus or strengthen their efforts toward attitudinal learning with respect to environmental issues, which leads to the question of how we can affect such attitudinal change. To some extent, many of us already attempt to influence our students' attitudes toward a variety of issues, such as diversity, cross-cultural differences, sexual harassment, ethical behavior, and even the recent emphasis on the "triple bottom line." And many business schools are already implementing programs, such as service learning, that are designed to facilitate attitude change and moral development (e.g., Rhee \& Sigler, 2010). Based on our results, if business schools are able to reduce the narcissistic tendencies among their students, then their attitudes regarding material- ism and ecological issues may improve. Table 2 presents a set of proposed interventions that are likely to influence narcissism directly (the first column in the table). Because many of the interventions intended to influence narcissism levels are essentially strategies for attitude change, they are likely to affect materialism and environmental ethics as well (as indicated by an " $x$ " in the second and third columns). Taken together, the indicated interventions promise to have an effect on materialism and environmental values that is direct and also indirect (through narcissism).

The interventions range from one-on-one interactions between the instructor and student, to changes that can be implemented in a single class, to initiatives that are best made on the college-wide level (see Bergman et al., 2010). We address each of these levels of intervention in turn. So as not to be redundant with Bergman et al. (2010), we do not discuss each proposed intervention here; rather, we discuss those interventions that require some explanation beyond their labels (i.e., their labels are too vague to give an indication of the intervention's nature), those interventions that share mechanisms in common, and those interventions not included in the Bergman et al. article.

One-on-One Interventions. One-on-one interventions involve direct interaction between the student and instructor. They include the following:

building an alliance (letting the students know that you are on their side), modeling desired behaviors, and suggesting that students try a different point of view. These steps are facilitated to the extent that class sizes are small, which is listed in Table 2 as a college-wide intervention. In cases of clinical narcissism, the best one-on-one intervention is to refer the student to a counselor, though narcissists are not likely to accept professional help 
except when, as Bergman et al. (2010) put it, "Fate has been unkind" ( $p$. 124).

Classroom Interventions. Most of the classroom interventions represent measures that many instructors take as a matter of course, without necessarily tailoring them specifically to reducing the levels of the variables in this study. Frequent assessments, for example, such as quizzes on nearly every class day, are thought to desensitize narcissistic students to evaluation. If evaluation is given infrequently and in large doses, it might be seen as a threat to a narcissist's (surprisingly fragile) self-concept. Enhanced use of devil's advocates (legitimized by the instructor) during class discussions and introducing peer evaluations on some student products might also desensitize narcissists to criticism by presenting it in a constructive, nonhierarchical, and less threatening way. Case method teaching and the use of role-plays may also be used to build empathy and an improved understanding and respect for the perspectives of others, which tend to be lacking in narcissists. In addition, improving the accuracy of students' expectations for a course may be managed by the frequency and effectiveness of an instructor's communication of their expectations of student engagement and performance to the class. Finally, guest speakers, particularly those viewed as of high status, are likely to have an effect on student attitudes, as narcissists tend to give greater weight to the pronouncements of high-status individuals. 
Table 2. Identifying Interventions That Would Likely Have an Effect on Narcissism, Materialism, and Environmental Ethics.

\begin{tabular}{|c|c|c|c|}
\hline $\begin{array}{l}\text { Intervention level/ } \\
\text { intervention }\end{array}$ & Narcissism & Materialism & Environmental ethics \\
\hline \multicolumn{4}{|l|}{ One-on-one } \\
\hline Build an alliance & $\mathrm{x}$ & $\mathbf{x}$ & $\mathrm{x}$ \\
\hline Carefully challenge & $\mathrm{x}$ & $x$ & $\mathrm{x}$ \\
\hline Modeling & $x$ & $x$ & $x$ \\
\hline Suggest behaviors & $\mathrm{x}$ & $x$ & $x$ \\
\hline \multicolumn{4}{|l|}{ Classroom } \\
\hline $\begin{array}{l}\text { Increase frequency of } \\
\text { assessment }\end{array}$ & $\mathrm{x}$ & & \\
\hline Devil's advocacy & $x$ & $\mathbf{x}$ & \\
\hline Peer evaluations & $x$ & & \\
\hline Case teaching & $\mathrm{x}$ & $\mathrm{x}$ & $\mathrm{x}$ \\
\hline Socratic method & $x$ & $x$ & $x$ \\
\hline Role-plays & $x$ & $x$ & $x$ \\
\hline Service learning & $x$ & $x$ & $x$ \\
\hline Personality inventories & $\mathrm{x}$ & $x$ & \\
\hline Communicate expectations & $x$ & & \\
\hline Guest speakers & $\mathrm{x}$ & $\mathrm{x}$ & $\mathrm{x}$ \\
\hline Field trips to poorer areas & $\mathrm{x}$ & $x$ & $\mathrm{x}$ \\
\hline \multicolumn{4}{|l|}{ College-wide } \\
\hline Smaller class sizes & $x$ & & \\
\hline Combat grade inflation & $\mathrm{x}$ & & \\
\hline Discourage ostentation & & $x$ & \\
\hline Internships & $x$ & $\mathbf{x}$ & $x$ \\
\hline $\begin{array}{l}\text { Study abroad (especially in } \\
\text { poorer countries) }\end{array}$ & $\mathrm{x}$ & $\mathrm{x}$ & $\mathrm{x}$ \\
\hline $\begin{array}{l}\text { Study abroad combined with } \\
\text { service learning }\end{array}$ & $\mathrm{x}$ & $x$ & $\mathrm{x}$ \\
\hline
\end{tabular}

Source. Bergman, Westerman, and Daly (20I0).

Note. " $x "=$ potential effect.

College-Wide Measures. College-wide measures include, for example, reducing class sizes and acting to reduce grade inflation (in order to discourage instructors from pandering to assertive narcissistic students). Materialism may also be influenced by initiating policies to discourage 
ostentation. For instance, at our university, freshmen and sophomores are not permitted to park their cars on campus, which has the effect of discouraging those students from gauging each other's socioeconomic levels by comparing the kinds of cars they drive. In addition, the local bus service is free (and has implications for environmental ethics). A further possibility to reduce ostentation-one that may not be practical for many business schools-might be to introduce dress codes to reduce social comparison.

Perhaps the strongest effects will be seen by college-wide (or universitywide) initiatives that are likely to affect two or more of the study's variables directly. For example, at our university, a short-term (2-week) study abroad to Malawi was developed. Malawi is one of the world's poorest countries: Only six percent of Malawi's residents have electricity, and many of them see prolonged outages each day. The trip's leaders noticed changes in the stu- dents' empathy levels (lack of empathy is a key component of narcissism) and in their appreciation of the basic elements of life, which middle-class Americans often take for granted (related to materialism). The study abroad focused on a service mission with environmental impacts, as the students helped craft a business plan for a corn mill in one of Malawi's villages and gave management advice to a nongovernmental organization engaged in promoting sustainable agriculture practices.

A college-wide curriculum change that would support environmental ethics would be the integration of the World Business Council on Sustainable Development's (2011) guiding principles. In addition, more traditional approaches may include a greater emphasis on the integration of sustainability-focused formalized service learning, real-world internships, and ethics and sustainability case studies and courses into the business core curriculum to combat business students' higher levels of narcissism.

\section{Need for Future Research}

It is possible that the dual trends of enhanced narcissism and environmental ethics may represent contradictory forces among younger generation business students. Also, materialism may function to enhance (or reduce) the cognitive dissonance that may result from this potential gap between espoused values and values in use. Thus, it may be that narcissists claim to have environmentally conscious attitudes but behave in ways that are not environmentally-friendly. As this study relied on selfreport data, further exploration of the nature of the interrelationships suggested by the results of this study would be useful in determining more 
explicit intervention strategies in improving student environmental ethics in management education. Future research may also specifically evaluate the effectiveness of the proposed interventions (summarized in Table 2) in reducing the levels of narcissism and materialism and enhancing the environmental ethics of business students at the one-on-one, classroom, and college-wide levels.

Additionally, business students' elevated levels of narcissism may be an issue internationally. Foster, Campbell, and Twenge (2003) completed a study that indicated narcissism by world region. The United States scored the highest in narcissism, with Europe following closely behind. Thus, a study of the relationships between narcissism, materialism, and ecological values in a cross-cultural context may allow for an enhanced understanding among management educators of these important relationships.

Future research could also further examine the relationships proposed in the present study across different business majors, in business graduate students, and among management practitioners. Such research could enhance our understanding of individuals' decision-making processes by utilizing an experimental design and a policy-capturing approach. Directly studying how both future and current organizational managers might perceive and respond to a variety of business scenarios could shed additional light on the influence of narcissism and materialism on environmentally ethical behavior.

Finally, because the correlations found in the current study indicated small to medium effects, there obviously remains variance that is unaccounted for in predicting environmental ethics with narcissism and materialism. Thus, other stable personality traits, such as conscientiousness, dogmatism, and Machiavellianism, could be examined to determine their potential influence on environmental ethics.

\section{DECLARATION OF CONFLICTING INTERESTS}

The author(s) declared no potential conflicts of interest with respect to the research, authorship, and/or publication of this article.

\section{FUNDING}

The author(s) received no financial support for the research, authorship, and/or publication of this article. 


\section{NOTE}

1. This is a cross-disciplinary paper involving the Department of Management, the Department of Psychology and Sustainable Development at Appalachian State University.

\section{REFERENCES}

Ameen, E. C., Guffey, D., \& McMillan, J. (1996). Gender differences in determining the ethical sensitivity of future accounting professionals. Journal of Business Ethics, 15, 591-597.

American Psychological Association. (2000). Diagnostic and statistical manual of mental disorders (4th ed., text rev.). Washington, DC: Author.

Arlow, P. (1991). Personal characteristics in college students' evaluations of business ethics and corporate social responsibility. Journal of Business Ethics, 10, 63-69.

Aspen Institute. (2001). Where will they lead? MBA student attitudes about business and society. New York, NY: Aspen Institute for Social Innovation through

Business. Bamberg, S., \& Schmidt, P. (2003). Incentives, morality, or habit? Predicting students' car use for university routes with the models of Ajzen, Schwartz, and

Triandis. Environment \& Behavior, 35, 264-285. Baron, R. A., \& Byrne, D. (1997). Social psychology (8th ed.). Boston, MA: Allyn \& Bacon. Beekun, R., Stedham, Y., Westerman, J., \& Yamamura, J. (2010). Effects of justice and utilitarianism on ethical decision-making: A cross-cultural examination of gender similarities and differences. Business Ethics: A European Review, 19, 309-325.

Belk, R. W. (1985). Materialism: Trait aspects of living in the material world. Journal of Consumer Research, 12, 265-280.

Bergman, J., Westerman, J., \& Daly, J. (2010). Narcissism in management education. Academy of Management Learning \& Education, 9, 119-131.

Blickle, G., Schlegel, A., Fassbender, P., \& Klein U. (2006). Some personality cor- relates of business white-collar crime. Applied Psychology: An International Review, 55, 220-233.

Boldizar, J., Wilson, K., \& Deemer, D. (1989). Gender, life experiences, and moral judgment development: A process-oriented approach. Journal of Personality and Social Psychology, 57, 229-238. 
Campbell, W. K., Bush, C. P., Brunell, A. B., \& Shelton, J. (2005). Understanding the social costs of narcissism: The case of the tragedy of the commons.

Personality and Social Psychology Bulletin, 31, 1358-1368.

Campbell, W. K., Goodie, A. S., \& Foster, J. D. (2004). Narcissism, confidence, and risk-attitude. Journal of Behavioral Decision Making, 17, 297-311.

Carrington, M. J., Neville, B. A., \& Whitwell, G. J. (2010). Why ethical consumers don't walk their talk: Towards a framework for understanding the gap between the ethical purchase intentions and actual buying behavior of ethically minded consumers. Journal of Business Ethics, 97, 139-158.

Chang, L., \& Arkin, R. M. (2002). Materialism as an attempt to cope with uncertainty. Psychology \& Marketing, 19, 389-406.

Cisek, S. Z., Hart, C. M., \& Sedikides, C. (2008). Do narcissists use material possessions as a primary buffer against pain? Psychological Inquiry, 19, 205207.

Cohen, J. (1988). Statistical power analysis for the behavioral sciences (2nd ed.). Hillsdale, NJ: Lawrence Earlbaum.

De Groot, J. I. M., \& Steg, L. (2008). Value orientations to explain beliefs related to environmental significant behavior: How to measure egoistic, altruistic, and biospheric value orientations. Environment \& Behavior, 40, 330-354.

Diekmann, A., \& Preisendorfer, P. (1998). Environmental behavior:

Discrepancies between aspirations and reality. Rationality and Society, 10, 79103.

Dunlap, R. E., Van Liere, K. D., Mertig, A. G., \& Jones, R. E. (2000). Measuring endorsement of the new ecological paradigm: A revised NEP scale. Journal of Social Issues, 56, 425-443.

Foster, J. D., Campbell, W. K., \& Twenge, J. M. (2003). Individual differences in narcissism: Inflated self-views across the lifespan and around the world. Journal of Research in Personality, 37, 469-486.

Fransson, N., \& Gärling, T. (1999). Environmental concern: Conceptual definitions, measurement methods, and research findings. Journal of Environmental Psychology, 19, 369-382. Gaudelli, J. (2009, April 29). The greenest generation. Advertising Age. Retrieved from http://adage.com/article/goodworks/truth-millennials-green-movement/136331/

Giacalone, R. A., \& Wargo, D. T. (2009). The roots of the global financial crisis are in our business schools. Journal of Business Ethics Education, 6, 147-168. Gilligan, C. (1977). In a different voice: Women's conceptions of self and morality. 
Harvard Educational Review, 47, 481-517. Gilligan, C. (1982). In a different voice: Psychological theory and women's development. Cambridge, MA: Harvard University Press.

Griskevicius, V., Tybur, J. M., \& Van den Bergh, B. (2010). Going green to be seen: Status, reputation, and conspicuous conservation. Journal of Personality and Social Psychology, 98, 392-404.

Haigh, N., \& Griffiths, A. (2009). The natural environment as a primary stakeholder: The case of climate change. Business Strategy and the Environment, 18, 347-359.

Hanks, K., Odom, W., Roedl, D., \& Blevis, E. (2008). Sustainable millennials: Attitudes towards sustainability and the material effects of interactive technologies. In Proceedings of the 26th annual SIGCHI conference on Human Factors in

Computing Systems (pp. 333-342). New York, NY: ACM. Hardin, G. (1968). The tragedy of the commons. Science, 162, 1243-1248. Hawken, P. (1993). The ecology of commerce: A declaration of sustainability. NewYork, NY: Harper Business.

Heilman, M., Block, C., Martell, F., \& Simon, M. (1989). Has anything changed? Current characterizations of men, women, and managers. Journal of Applied Psychology, 74, 935-942.

Hofstede, G. (Ed.). (1998). Masculinity and femininity: The taboo dimension of national cultures. Thousand Oaks, CA: Sage.

Horvath, S., \& Morf, C. C. (2009). Narcissistic defensiveness: Hypervigilance and avoidance of worthlessness. Journal of Experimental Social Psychology, 45, 1252-1258.

Inglehart, R. (1990). Culture shift in advanced industrial society. Princeton, NJ: Princeton University Press.

Intergovernmental Panel on Climate Change. (2007). IPCC fourth assessment report. Retrieved from

http://www.ipcc.ch/publications_and_data/publications_and_data_reports.shtml

Jöreskog, K. G., \& Sörbom, D. (2006). LISREL 8.8 for Windows [Computer software]. Skokie, IL: Scientific Software International.

Kaiser, F. G., Ranney, M., Hartig, T., \& Bowler, P. A. (1999). Ecological behavior, environmental attitude, and feelings of responsibility for the environment. European Psychologist, 4(2), 59-74. 
Kasser, T., \& Ryan, R. M. (1996). Further examining the American dream: Differential correlates of intrinsic and extrinsic goals. Personality and Social Psychology Bulletin, 22, 280-287.

Kasser, T., \& Kanner, A. (Eds.). (2004). Psychology and consumer culture, the struggle for a good life in a materialistic world. Washington, DC: American Psychological Association.

Kernis, M. H., \& Sun, C. (1994). Narcissism and reactions to interpersonal feedback. Journal of Research in Personality, 28, 4-13.

Khazanchi, D. (1995). Unethical behavior in information systems: The gender factor. Journal of Business Ethics, 14, 741-749.

Kilbourne, W., \& Pickett, G. (2008). How materialism affects environmental beliefs, concern, and environmentally responsible behavior. Journal of Business Research, 61, 885-893.

Kohlberg, L. (1981). The philosophy of moral development. San Francisco, CA: Harper \& Row.

Kohlberg, L. (1984). The psychology of moral development. San Francisco, CA: Harper \& Row.

Lasch, C. (1978). The culture of narcissism: American life in an age of diminishing expectations. New York, NY: W. W. Norton.

Lifton, P. (1985). Individual differences in moral development: The relation of sex, gender, and personality to morality. Journal of Personality, 53, 306-334.

Linden, E. (1979). Affluence and discontent: The anatomy of consumer societies. New York, NY: Viking.

Millon, T. (1996). Disorders of personality. DSM-IV and beyond (2nd ed.). New York, NY: Wiley-Interscience.

Morf, C. C., \& Rhodewalt, F. (2001). Unraveling the paradoxes of narcissism: A dynamic self-regulatory processing model. Psychological Inquiry, 12, 177-196.

Pfeffer, J. (2005). Why do bad management theories persist? A comment on Ghoshal. Academy of Management Learning \& Education, 4, 96-100.

Preacher, K. J., \& Hayes, A. F. (2004). SPSS and SAS procedures for estimating indirect effects in simple mediation models. Behavior Research Methods, Instruments, \& Computers, 36, 717-731. 
Preacher, K. J., \& Hayes, A. F. (2008). Asymptotic and resampling strategies for assessing and comparing indirect effects in multiple mediator models. Behavior Research Methods, 40, 879-891.

Princen, T. (1997). The shading and distancing of commerce: When internalization is not enough. Ecological Economics, 20, 235-253.

Raskin, R., \& Terry, H. (1988). A principal-components analysis of the Narcissistic Personality Inventory and further evidence of its construct validity. Journal of Personality and Social Psychology, 54, 890-902.

Rest, J. (1986). Moral development: Advances in theory and research. New York, NY: Praeger.

Richins, M. L., \& Dawson, S. (1992). A consumer values orientation for materialism and its measurement: Scale development and validation. Journal of Consumer Research, 19, 303-316.

Rhee, K. S., \& Sigler, T. H. (2010). Developing enlightened leaders for industry and community: Executive education and service-learning. Journal of Management Education, 34, 163-181.

Rhodewalt, F., \& Morf, C. C. (1995). Self and interpersonal correlates of the Narcissistic Personality Inventory: A review and new findings. Journal of Research in Personality, 29, 1-23.

Robak, R., Chiffriller, S., \& Zappone, M. (2007). College students' motivations for money and subjective well-being. Psychological Reports, 100, 147-156.

Robertson, C. A. (2008). An analysis of 10 years of business ethics research in Strategic Management Journal: 1996-2005. Journal of Business Ethics, 80, 745753.

Rochberg-Halton, E. (1986). Meaning and modernity: Social theory in the pragmatic attitude. Chicago, IL: University of Chicago Press.

Rodin, G., \& Izenberg, S. (1996). Treating the narcissistic personality disorder. In M. Rosenbluth \& I. D. Yalom (Eds.), Treating difficult personality disorders (pp. 107-122). San Francisco, CA: Jossey-Bass.

Rose, P. (2007). Mediators of the association between narcissism and compulsive buying: The roles of materialism and impulse control. Psychology of Addictive Behaviors, 21, 576-581.

Ruegger, D., \& King, E. (1992). A study of the effect of age and gender upon student business ethics. Journal of Business Ethics, 11, 179-186. 
Schein, V. A. (1973). The relationship between sex role stereotypes and requisite management characteristics. Journal of Applied Psychology, 57, 95-100.

Schminke, M., Ambrose, M., \& Miles, J. A. (2003). The impact of gender and setting on perceptions of others' ethics. Sex Roles, 48, 361-375.

Schultz, P. W. (2000). Empathizing with nature: The effects of perspective taking on concern for environmental issues. Journal of Social Issues, 56, 391-406.

Speth, J. G. (2009). The bridge at the edge of the world: Capitalism, the environment, and crossing from crisis to sustainability. New Haven, CT: Yale University Press.

Stern, P., \& Dietz, T. (1994). The value basis of environmental concern. Journal of Social Issues, 50, 65-84.

Svanstrom, M., Lozano-Garcia, S., \& Rowe, D. (2008). Learning outcomes for sus- tainable development in higher education. International Journal of Sustainability in Higher Education, 9, 339-351.

Thoma, S. (1986). Estimating gender differences in the comprehension and prefer- ence of moral issues. Developmental Review, 6, 165-180.

United Nations. (2004). Environmental ethics (Policy Document). Retrieved from http://portal.unesco.org/shs/es/files/7561/11133014821PolicyDocumentEE_1. pdf/PolicyDocumentEE_1.pdf

Vansteenkiste, M., Duriez, B., Simons, J., \& Soenens, B. (2006). Materialistic values and well-being among business students: Further evidence of their detrimental effect. Journal of Applied Social Psychology, 36, 2892-2908.

Wehrmeyer, W., \& McNeil, M. (2000). Activist, pragmatists, technophiles and tree- huggers? Gender differences in employees' environmental attitudes. Journal of Business Ethics, 28, 211-222.

Westerman, J. W., Bergman, J. Z., Bergman, S. M., \& Daly, J. P. (2012). Are universities creating millennial narcissistic employees? An empirical examination of narcissism in business students and its implications. Journal of Management Education, 36, 5-32.

Whipple, T., \& Swords, D. (1992). Business ethics judgments: A cross-cultural com- parison. Journal of Business Ethics, 11, 671-678.

White, J. (1992). Business, ethics, and Carol Gilligan's "two voices." Business Ethics Quarterly, 2, 51-61.

White, J. (1994). Individual characteristics and social knowledge in ethical reasoning. Psychological Reports, 75, 627-649. 
Williams, R. J., Barrett, J. D., \& Brabston, M. (2000). Managers' business school edu- cation and military service: Possible links to corporate criminal activity. Human Relations, 53, 691-712.

World Business Council on Sustainable Development. (2011). Mission statement and guiding principles. Retrieved from http://www.wbcsd.org/templates/ TemplateWBCSD5/layout.asp?type=p\&Menuld=NjA\&doOpen=1\&ClickMenu $=$ LeftMenu 